Research Article

\title{
A Revised Grey Relational Analysis Method for Multicriteria Group Decision-Making with Expected Utility Theory for Oil Spill Emergency Management
}

\author{
Wenshuai Wu \\ Guangdong Academy of Decision Sciences, Sun Yat-sen University, Guangzhou 510275, China \\ Correspondence should be addressed to Wenshuai Wu; wuwsh8@163.com
}

Received 28 October 2020; Revised 25 February 2021; Accepted 10 March 2021; Published 30 March 2021

Academic Editor: Harish Garg

Copyright (c) 2021 Wenshuai Wu. This is an open access article distributed under the Creative Commons Attribution License, which permits unrestricted use, distribution, and reproduction in any medium, provided the original work is properly cited.

\begin{abstract}
The substantial importance and complexity of oil spill emergency management have been confirmed by the massive, disastrous oil spill accidents that have occurred in recent years. The goal of this study is to research and develop an effective new model to accurately respond to oil spill emergencies for the purpose of disaster risk reduction. In this model, firstly, grey relational analysis is used to treat the variable and complex environment of an oil spill. Secondly, a revised grey relational analysis method based on the concept of angle between two vectors is presented to optimize assessment accuracy by measuring the similarity between the reference series and alternative series. Thirdly, by incorporating expected utility theory, a revised grey relational analysis for facilitating consensus is developed for multicriteria group decision-making. Finally, an empirical study on oil spill emergency management is discussed to demonstrate the feasibility and effectiveness of the proposed model for oil spill emergency management in a complex environment to reduce disaster risk.
\end{abstract}

\section{Introduction}

In recent years, major emergencies have occurred with increasing frequency, including the $9 / 11$ attack in the United States in 2001, the SARS epidemic in 2003, the Indian Ocean tsunami in 2004, the Chinese Wenchuan earthquake in 2008, the Myanmar tropical cyclone Nargis in 2008, the Japanese 9.0-magnitude earthquake in 2011, Thailand's floods in 2011, the Hurricane Sandy in the United States in 2012, European floods of the century in 2013, the Ebola outbreak in 2014, the California shooting incident in 2015, the Nice attack in 2016, thallium pollution of the Jialing River in 2017, the Kuwait Heavy Sandstorm in 2018, and the COVID-19 pandemic. Frequent occurrence of unexpected events has resulted in numerous cases of environmental pollution, ecological damage, property losses, and casualties. Therefore, emergency management during a complex environment has become a global concern.

Accidental oil spill emergency is a significant event that can affect environmentally, ecologically, and economically sensitive marine areas. Massive, disastrous oil spill incidents have also caused a great amount of property losses and casualties $[1,2]$. After an oil spill occurs, it is necessary to accurately respond within the shortest possible time to protect marine species and minimize cleanup and damage costs [3]. Since 2007, oil spill accidents have increased worldwide, such as the oil spill in the Russian Arctic in December 2007, the Gulf of Mexico oil spill in the United States in April 2010, the Bohai Bay oil spill in China in June 2011, the Alberta oil spill in Canada in 2012, the marine oil spill in Thailand in 2013, the oil spill in Galveston Bay in the United States in 2014, the crude oil spill in Wayaobao in China in 2015, the California oil spill emergency in 2016, the Dalian oil pipeline explosion accident in 2017, a sudden explosion of the Panamanian tanker "Sangji" in 2018, and the oil spill in Brazil in 2019. These oil spill accidents have led to substantial environmental pollution, ecological damage, property losses, and casualties, which have been acknowledged by stakeholders, such as environment agencies, oil companies, and nongovernmental organizations. The 
question of how to effectively respond to oil spill emergencies in a complex environment for the purpose of disaster risk reduction and formulation of crisis response strategies has become a challenging issue worldwide.

It has also promoted the theoretical research and technology development to deal with emergency problems during a complex environment. Lin et al. [4] developed multiattribute group decision-making methods under probabilistic uncertain linguistic complex environment. Qiyas et al. [5] proposed the concept of Yager operators with the picture fuzzy set environment for emergency program selection. Lin et al. [6] applied MULTIMOORA-based MCDM model for site selection of car-sharing station under picture fuzzy and complexity environment. Garg and Arora [7] proposed a TOPSIS method based on correlation coefficient for solving complexity decision-making problems with intuitionistic fuzzy soft set information. Wu et al. [8] proposed and developed a DMSECA model to evaluate clustering algorithms by merging expert wisdom in order to reconcile differences in their evaluation performance for information fusion during a complex decision-making process.

The objective of the present study is to research and develop an effective model to aid decision-makers involved in oil spill emergency and crisis response planning for a complex environment. It is necessary to minimize the damage and costs caused by potential oil spills and to devise a contingency plan for emergency situations and crisis management [9-11]. However, the design and development of an optimal emergency plan is very difficult to achieve because it depends on many variables within a dynamic and complex environment comprising the changing nature of the ocean environment, type of oil, spilled volume, location of the oil spill, and weather. Hence, this can be considered a multicriteria decision-making (MCDM) problem. Grey relational analysis, one of the classical MCDM methods, is a basic method of grey system theory [12-16] that is used to analyze the data changes in the trend curve by comparing the similarity degree of each data sequence with the reference sequence [17-19]. This method can process inaccurate and vague information associated with a variable; it can work with an uncertain and ambiguous environment; and it only requires a reasonable amount of sample data. Thus, in this study, grey relational analysis is applied to address the dynamics and complexities of the variables associated with the environment in oil spill emergency management. This paper simulates oil spill scenarios using the computational package OILMAP [20].

Following oil spill emergencies, many entities-such as environmental agencies, oil companies, and nongovernmental organizations-are involved in the decision-making process to advance their own benefits and interests [9]. Consequently, there is an inevitable conflict among these institutions in the decision-making process with respect to choosing the best emergency response alternatives. In this situation, a consensus decision that increases the level of satisfaction among multiple stakeholders is of considerable importance. Hence, a multicriteria group decision-making (MCGDM) approach based on group wisdom is proposed to model the oil spill emergency response to reduce disaster risk.

Besides, this paper takes into account the evaluation accuracy for an effective and rapid emergency response and introduces the mathematical concept of angle between two vectors to improve the similarity characterization process of grey relational analysis by measuring the similarity between the reference series and alternative series. In the MCGDM process, expected utility theory is applied to aggregate individual preferences into a group's consensus.

Considering all of these factors, the motivation of this work is to research and develop an effective model to aid decision-makers involved in oil spill emergency and crisis response planning for a complex environment. In this paper, a revised grey relational analysis method using MCGDM with expected utility theory is proposed to respond to oil spill emergencies for disaster risk reduction when a variety of stakeholders and a variable and complex oil spill environment are involved. The main contributions of this study are as follows:

(1) A revised grey relational analysis for group decisionmaking technique is proposed to evaluate and implement an emergency plan for responding to unexpected events related to an oil spill.

(2) In this proposed technique, grey relational analysis is firstly applied to the variable and complex environment. Secondly, based on the concept of angle between two vectors, a revised grey relational analysis method is presented to optimize assessment accuracy. Thirdly, by incorporating expected utility theory, a revised grey relational analysis for facilitating consensus is developed for multicriteria group decision-making.

(3) The proposed technique takes into account the influence of multiple criteria, a finite number of alternatives, the benefits and interests of multiple stakeholders, and the emergency decision simulation process under a variable and complex environment.

The rest of this study is organized as follows. Section 2 reviews related research. Section 3 introduces the foundations of grey relational analysis, angle between two vectors, and expected utility theory. In Section 4, a revised grey relational analysis method for MCGDM is proposed. In Section 5, an empirical study on oil spill emergency management in a complex environment is conducted to verify the proposed model. Section 6 concludes the study.

\section{Related Works}

Emergencies have a complex evolutionary process, and emergency decision-making is difficult to solve with traditional decision theory. Tufekci and Wallace [21] suggested that emergency management is essentially a complex multicriteria optimization problem. As defined by the International Society on Multiple Criteria Decision Making, MCDM is the study of methods and procedures by which concerns about multiple conflicting criteria can be formally 
incorporated into the management planning process [5, 22-27]. Over the past 40 years, MCDM has made remarkable progress and evolved into a mature discipline $[15,28-30]$. It has been used in a wide range of practical applications, such as information science, engineering systems, and decision-making [8, 31-36].

In general, multiple-criteria problems can be divided into two categories: multiple-criteria discrete alternative problems and multiple-criteria optimization problems [37]. Many methods and techniques have been developed to solve these two categories of problems [15, 38-40], such as data envelopment analysis (DEA) [41], the analytic hierarchy process (AHP) [42], grey relational analysis (GRA) [43], the compromise ranking method (called VIKOR) [31], the technique for ordering preference by similarity to ideal solution (TOPSIS) [44], the decision-making trial and evaluation laboratory (DEMATEL) [45], the preference ranking organization method for enrichment of evaluations (PROMETHEE) [46], multiattribute utility theory (MAUT) [47], and evolutionary multiobjective optimization [48].

In oil spill emergency management for disaster risk reduction, the benefits and interests of environmental agencies, oil companies, and nongovernmental organizations should be considered. Conflicts among these varied interests will inevitably arise in the decision-making process for choosing the best emergency plan. In this context, the process of evaluating and choosing the best emergency plan involves multiple criteria, multiple stakeholders, and a finite number of alternatives [49]. Therefore, oil spill emergency management for disaster risk reduction can be interpreted as a multicriteria group decision-making problem, which combines MCDM and GDM methods. MCGDM has been proven to be an effective technique for increasing the level of overall satisfaction of group members with respect to the final decision [50-54].

GRA, which is one of the best-known MCDM techniques, is a type of quantitative analysis that is used to measure the similarity between the reference series and an alternative series $[16,17,55-57]$. The alternative series with the closest similarity to the reference series is the best alternative for the problem at hand [58-61]. GRA is a part of grey theory, and it is based on the concept of grey space. It can process the inaccurate and vague information in grey systems under a variable environment [43]. The GRA method is a widely applied technique in data processing, system analysis, control systems, and decision-making $[19,55,62-67]$. Compared with conventional methods that require massive amounts of data, GRA possesses the following advantages [43, 68-70]: (1) It uses simple and easy calculations. (2) It only requires a reasonable amount of sample data. (3) It does not require a typical distribution of samples. (4) The quantified outcomes from the grey relational grade do not result in conclusions that are contradictory to the qualitative analysis. (5) The grey relational grade model is a transfer functional model, which is suitable and effective for dealing with discrete data $[43,57,68,69]$. It is difficult to design and develop the best oil spill emergency plan to reduce disaster risk because the process depends on a multivariable, changing, and complex environment that involves factors such as the dynamic nature of the ocean environment, type of oil, spilled volume, location of the oil spill, and weather. In this study, based on GRA's advantages and the concept of grey space, GRA is applied to address the complexities of the changing oil spill environment in order to reduce disaster risk.

GRA aims to measure the similarity between the reference series and alternative series. Therefore, in this study, the mathematical concept of the angle between two vectors is applied to improve the conventional GRA method. In geometry, an angle is defined as the figure formed by two rays (called the sides of the angle) sharing a common endpoint (called the vertex of the angle) [71]. The angle between two vectors is in the range $0 \leq \cos (\alpha, \beta) \leq 1$. The higher the value of $\cos (\alpha, \beta)$ is, the higher the similarity between the directions of vectors $\alpha$ and $\beta$ is. In contrast, the smaller the value of $\cos (\alpha, \beta)$ is, the higher the dissimilarity between the directions of vectors $\alpha$ and $\beta$ is. Thus, the angle between two vectors can be used to measure the similarity between the reference series and alternative series. In this study, the reference series and alternative series are regarded as vectors.

The group decision-making problem arises in many realworld decision-making situations [72-75]. In MCGDM problems, the essence is how to effectively aggregate individual preferences into a group consensus. Ishizaka and Labib [76] noted that there are four ways to combine individual preferences into a group consensus [77, 78]. In this study, expected utility theory is used to aggregate individual preferences.

Expected utility theory is a formal mathematical tool that was designed to aid decision-makers in choosing among many possible choices to balance risk and reward [79, 80]. It is widely used to address risk and uncertainty decisions in economics, finance, insurance, and management science [81-83]. Arrow and Lind [84] indicated that when decisionmakers are in a risk-neutral state, it is possible for them to reach a consensus within a group of stakeholders [85, 86]. Expected utility theory holds that decision-makers choose among risky and uncertain prospects by comparing their expected utility values, which are the weighted sums obtained by adding the utility values of outcomes multiplied by their respective probabilities [87]. In this study, expected utility theory is used to facilitate consensus in a group decision-support system.

\section{Preliminaries}

MCGDM is a decision-making procedure that is used to find the best satisfactory solution that increases the level of overall satisfaction of the group members with the final decision. MCGDM has the virtue of drawing on the wisdom of masses [73]. In an MCGDM problem, a group of decisionmakers is formed to help rank a finite set of alternatives more rationally by aggregating the individual preferences considering the decision-makers' respective knowledge, experience, and expertise for the decision space $[88,89]$. In the following subsections, this paper describes some MCDM techniques such as GRA, present the basic concepts of an angle between two vectors, and summarize expected utility theory. 
3.1. Grey Relational Analysis. Grey theory was developed by Deng [43] to determine the degree of relation among various alternatives in an MCDM problem [69]. GRA is a part of grey theory. It has been used to handle imprecise and vague information in grey systems under variable factors and a changing environment [55]. GRA aims to measure the degree of similarity between the reference series and alternative series, which is suitable for solving problems with complicated interrelationships among multiple factors and multiple variables $[19,90]$. This only requires a reasonable amount of sample data, and it uses a simple calculation. The specific steps are presented as follows [91].

The decision matrix $R$ of a multicriteria problem with $m$ alternatives and $n$ criteria is given as in the following equation:

$$
R=\left[\begin{array}{cccc}
x_{11} & x_{12} & \ldots & x_{1 n} \\
x_{21} & x_{22} & \ldots & x_{2 n} \\
\vdots & \vdots & \vdots & \vdots \\
x_{m 1} & x_{m 2} & \ldots & x_{m n}
\end{array}\right] .
$$

(1) Standardize the raw matrix $R$ : The standardization process is as follows:

(a) The Larger-the-Better (LB): the larger objective value is better (e.g., the benefit), and it can be expressed by

$$
x_{i j}^{\prime}=\frac{x_{i j}-\min _{i} x_{i j}}{\max _{i} x_{i j}-\min _{i} x_{i j}} .
$$

(b) The Smaller-the-Better (SB): the smaller objective value is better (e.g., the cost and defects), and it can be represented as follows:

$$
x_{i j}^{\prime}=\frac{\max _{i} x_{i j}-x_{i j}}{\max _{i} x_{i j}-\min _{i} x_{i j}} .
$$

(c) The Nominal-the-Better (NB): the value closer to the objective value $x_{o b}$ is better, and it can be represented as follows:

$$
x_{i j}^{\prime}=1-\frac{\left|x_{i j}-x_{o b}\right|}{\max \left\{\max _{i} x_{i j}-x_{o b} ; x_{o b}-\min _{i} x_{i j}\right\}} .
$$

(2) Construct the normalized matrix $R^{\prime}$ :

$$
R^{\prime}=\left[\begin{array}{cccc}
x_{11}^{\prime} & x_{12}^{\prime} & \ldots & x_{1 n}^{\prime} \\
x_{21} & x_{22} & \ldots & x_{2 n}^{\prime} \\
\vdots & \vdots & \vdots & \vdots \\
x_{m 1}^{\prime} & x_{m 2}^{\prime} & \ldots & x_{m n}^{\prime}
\end{array}\right] .
$$

(3) Generate the reference series $x^{\prime}(0)$ :

$$
x^{\prime}(0)=\left(x_{11}^{\prime}(0), x_{12}^{\prime}(0), \ldots, x_{1 j}^{\prime}(0), \ldots, x_{1 n}^{\prime}(0)\right),
$$

where $x_{1 j}^{\prime}(0)$ is the reference value in relation to the $\mathrm{j}$ th factor. It is determined by the largest and normalized value of each factor.
(4) Calculate all differences $\Delta_{i j}(0)$ between all the normalized alternative series and the reference series $x^{\prime}(0)$ :

$$
\begin{aligned}
\Delta_{i j}(0) & =\left|x^{\prime}(0)-x_{i j}^{\prime}\right|, \\
\Delta & =\left[\begin{array}{cccc}
\Delta_{11}(0) & \Delta_{12}(0) & \ldots & \Delta_{1 n}(0) \\
\Delta_{21}(0) & \Delta_{22}(0) & \ldots & \Delta_{2 n}(0) \\
\vdots & \vdots & \vdots & \vdots \\
\Delta_{m 1}(0) & \Delta_{m 2}(0) & \ldots & \Delta_{m n}(0)
\end{array}\right] .
\end{aligned}
$$

(5) Compute the grey relational coefficient $\gamma_{i j}(0)$ between all the normalized alternative series and the reference series:

$$
\gamma_{i j}(0)=\frac{\min _{i} \min _{j} \Delta_{i j}(0)+\delta \max _{i} \max _{j} \Delta_{i j}(0)}{\Delta_{i j}(0)+\delta \max _{i} \max _{j} \Delta_{i j}(0)},
$$

where $\delta$ is a distinguished coefficient. The value of $\delta$ is usually set to 0.5 to provide moderate distinguishing effects and good stability.

(6) Get the grey relational degree $\Gamma_{i}$ :

$$
\Gamma_{i}=\sum_{j=1}^{n}\left(w_{j} \times \gamma_{i j}(0)\right), \text { where } \sum_{j=1}^{m} w_{j}=1 .
$$

In this study, the weight vector $w_{j}$ of the semantic opinions for different stakeholders is applied to calculate the normalized weight of criteria.

3.2. Angle between Two Vectors. In Section 2, the definition of the angle between two vectors is introduced, which is the cosine formula related to two vectors. We know that the greater the value of $\cos (\alpha, \beta)$ is, the closer the direction of vector $\alpha$ is to that of $\beta$. We also know that a vector is composed of two parts: direction and norm. Now, this paper introduces the concept of the norm of a vector and the projection.

The norm of a vector is a function that assigns a strictly positive length or size to each vector in a vector space, rather than zero vector. Suppose that vector $\alpha=\left(\alpha_{1}, \alpha_{2}, \ldots, \alpha_{n}\right)$. The norm of vector $\alpha$ can be computed as follows [90]:

$$
\|\alpha\|=\sqrt{\sum_{j=1}^{n} \alpha_{j}^{2}}
$$

The projection represents the closeness degree of two vectors by considering the norm magnitude and angle between two vectors together, as the angle between two vectors reflects the similarity between the directions of the two vectors [92]. To measure the degree of similarity between the vectors from a global point of view, this paper uses the following formula for projection. 
Suppose that $\alpha=\left(\alpha_{1}, \alpha_{2}, \ldots, \alpha_{n}\right)$ and $\beta=\left(\beta_{1}, \beta_{2}\right.$, $\ldots, \beta_{n}$ ) are two vectors. The projection of vector $\alpha$ onto vector $\beta$ can be defined as follows [93]:

$$
\begin{aligned}
p(\alpha) & =\|\alpha\| \cos (\alpha, \beta)=\sqrt{\sum_{j=1}^{n} \alpha_{j}^{2}} \times \frac{\sum_{j=1}^{n}\left(\alpha_{j} \beta_{j}\right)}{\sqrt{\sum_{j=1}^{n} \alpha_{j}^{2}} \times \sqrt{\sum_{j=1}^{n} \beta_{j}^{2}}} \\
& =\frac{\sum_{j=1}^{n} \alpha_{j} \beta_{j}}{\sqrt{\sum_{j=1}^{n} \beta_{j}^{2}}} .
\end{aligned}
$$

Vector $\beta$ will be closer to vector $\alpha$ when the value of $p(\alpha)$ is larger. Hence, the projection of vector $\alpha$ onto vector $\beta$ can measure the degree of similarity between the vectors from a global point of view by considering the two parts of a vector: direction and norm.

3.3. Expected Utility Theory. Expected utility theory is a useful model for risk aversion, and it is widely applied in theoretical and practical analysis $[79,81,82]$. The underlying principle is that the decision-maker has prior knowledge of the probabilities of all the events that can occur. The decision-makers assign a value (e.g., a sum of money) to each alternative [85]. Expected utility theory aims to help decision-makers to choose among various possible choices to balance risk and reward using a formal, mathematical function. Arrow and Lind [84] argued that expected utility theory can help reach a decision-making consensus within a group of stakeholders [85].

The von Neumann-Morgenstern expected utility over a set of outcomes can be expressed as follows:

$$
U(x)=\sum_{i=1}^{n} u\left(x_{i}\right) p\left(x_{i}\right), \quad(1 \leq i \leq n),
$$

where $U(x)$ is the utility of all sets of possible outcomes; $u\left(x_{i}\right)$ is the utility of an outcome $x_{i}(i=1,2, \ldots n)$; and $p\left(x_{i}\right)$ is the probability of an outcome $x_{i}(i=1,2, \ldots, n)$, where $p\left(x_{i}\right) \geq 0$ for all $i=1,2, \ldots, n$ and $\sum_{i=1}^{n} p\left(x_{i}\right)=1$.

\section{Evaluation Model}

In this section, the developed model is proposed, which is a revised GRA method for facilitating consensus. The model is composed of two parts: a revised GRA method and MCGDM with expected utility theory.

4.1. Revised GRA Method. The GRA method analyzes the data change in the trend curve by measuring the similarity between the reference series and alternative series. The concept of an angle between two vectors can reflect the similarity between the directions of two vectors [93]. We know that the direction of vector $\alpha$ will be closer to that of $\beta$ when the value of $\cos (\alpha, \beta)$ is larger. The projection of vector $\alpha$ onto vector $\beta$ can reflect and measure the degree of similarity between the vectors from the global point of view by considering the two parts of a vector: direction and norm.
Hence, the projection of the angle between two vectors can be applied to express the closeness of the relationship between each alternative series and the reference series [93]. The detailed processes of the revised GRA method are as follows:

The decision matrix $R$ with $m$ alternatives and $n$ criteria is as follows:

$$
R=\left[\begin{array}{cccc}
x_{11} & x_{12} & \ldots & x_{1 n} \\
x_{21} & x_{22} & \ldots & x_{2 n} \\
\vdots & \vdots & \vdots & \vdots \\
x_{m 1} & x_{m 2} & \ldots & x_{m n}
\end{array}\right]
$$

(1) Standardize the raw matrix $R$ : the standardization process is described as follows:

(a) The Larger-the-Better (LB): the larger objective value is better (e.g., the benefit), which can be expressed by

$$
x_{i j}^{\prime}=\frac{x_{i j}-\min _{i} x_{i j}}{\max _{i} x_{i j}-\min _{i} x_{i j}} .
$$

(b) The Smaller-the-Better (SB): the smaller objective value is better (e.g., the cost and defects), which can be represented as follows:

$$
x_{i j}^{\prime}=\frac{\max _{i} x_{i j}-x_{i j}}{\max _{i} x_{i j}-\min _{i} x_{i j}}
$$

(c) The Nominal-the-Better (NB): the value closer to the objective value $x_{o b}$ is better, which can be represented as follows:

$$
x_{i j}^{\prime}=1-\frac{\left|x_{i j}-x_{o b}\right|}{\max \left\{\max _{i} x_{i j}-x_{o b} ; x_{o b}-\min _{i} x_{i j}\right\}} .
$$

(2) Construct the normalized matrix $R^{\prime}$ :

$$
R^{\prime}=\left[\begin{array}{cccc}
x_{11}^{\prime} & x_{12}^{\prime} & \ldots & x_{1 n}^{\prime} \\
x_{21} & x_{22} & \ldots & x_{2 n}^{\prime} \\
\vdots & \vdots & \vdots & \vdots \\
x_{m 1}^{\prime} & x_{m 2}^{\prime} & \ldots & x_{m n}^{\prime}
\end{array}\right] .
$$

(3) Generate the reference series $x^{\prime}(0)$ :

$$
x^{\prime}(0)=\left(x_{11}^{\prime}(0), x_{12}^{\prime}(0), \ldots, x_{1 j}^{\prime}(0), \ldots, x_{1 n}^{\prime}(0)\right),
$$

where $x_{1 j}^{\prime}(0)$ is the reference value in relation to the $\mathrm{j}$ th factor. It is determined by the largest and normalized value of each factor.

(4) Calculate all the differences $\Delta_{i j}(0)$ between all the normalized alternative series and the reference series $x^{\prime}(0)$ : 


$$
\begin{aligned}
\Delta_{i j}(0) & =\left|x^{\prime}(0)-x_{i j}^{\prime}\right|, \\
\Delta & =\left[\begin{array}{cccc}
\Delta_{11}(0) & \Delta_{12}(0) & \ldots & \Delta_{1 n}(0) \\
\Delta_{21}(0) & \Delta_{22}(0) & \ldots & \Delta_{2 n}(0) \\
\vdots & \vdots & \vdots & \vdots \\
\Delta_{m 1}(0) & \Delta_{m 2}(0) & \ldots & \Delta_{m n}(0)
\end{array}\right] .
\end{aligned}
$$

(5) Compute the grey relational coefficient $\gamma_{i j}(0)$ between all the normalized alternative series and the reference series:

$$
\gamma_{i j}(0)=\frac{\min _{i} \min _{j} \Delta_{i j}(0)+\delta \max _{i} \max _{j} \Delta_{i j}(0)}{\Delta_{i j}(0)+\delta \max _{i} \max _{j} \Delta_{i j}(0)},
$$

where $\delta$ is a distinguished coefficient. The value of $\delta$ is usually set to 0.5 to provide moderate distinguishing effects and good stability.

(6) Generate a grey correlation coefficient matrix $A$ between the normalized alternative series and the reference series:

$$
A=\left[\begin{array}{cccc}
\gamma_{11}(0) & \gamma_{12}(0) & \ldots & \gamma_{1 n}(0) \\
\gamma_{21}(0) & \gamma_{22}(0) & \ldots & \gamma_{2 n}(0) \\
\vdots & \vdots & \vdots & \vdots \\
\gamma_{m 1}(0) & \gamma_{m 2}(0) & \ldots & \gamma_{m n}(0)
\end{array}\right]
$$

(7) Calculate the weighted grey correlation coefficient matrix $B$ :

$$
B=\left[\begin{array}{cccc}
w_{1} \gamma_{11}(0) & w_{2} \gamma_{12}(0) & \ldots & w_{n} \gamma_{1 n}(0) \\
w_{1} \gamma_{21}(0) & w_{2} \gamma_{22}(0) & \ldots & w_{n} \gamma_{2 n}(0) \\
\vdots & \vdots & \vdots & \vdots \\
w_{1} \gamma_{m 1}(0) & w_{2} \gamma_{m 2}(0) & \ldots & w_{n} \gamma_{m n}(0)
\end{array}\right]
$$

The normalized weight of the criterion is determined by the weight vector $w_{j}$ of the semantic opinions for different stakeholders.

(8) Calculate the grey relational degree $\varepsilon$. The goal of grey relational degree is to measure the similarity between the reference series and alternative series, which indicates the projection of the normalized alternative series of each alternative onto the reference series. The concept of an angle between two vectors can reflect the similarity between two vectors. The projection of vector $\alpha$ onto vector $\beta$ can measure the degree of similarity between the vectors from a global point of view by considering the two parts of a vector: direction and norm. Hence, the projection of the angle between two vectors can be used to indicate the degree of similarity between the normalized alternative series and the reference series. Let vector $\alpha$ be the weighted grey correlation coefficient values of the normalized alternative series of each alternative, and let vector $\beta$ be the weighted grey correlation coefficient values of the reference series separately. So, the grey relational degree $\varepsilon$ can be calculated as follows:

$$
\begin{aligned}
\varepsilon=p(\alpha)=\|\alpha\| \cos (\alpha, \beta) & =\sqrt{\sum_{j=1}^{n} \alpha_{j}^{2} \times \frac{\sum_{j=1}^{n}\left(\alpha_{j} \beta_{j}\right)}{\sqrt{\sum_{j=1}^{n} \alpha_{j}^{2}} \times \sqrt{\sum_{j=1}^{n} \beta_{j}^{2}}}} \\
& =\frac{\sum_{j=1}^{n} \alpha_{j} \beta_{j}}{\sqrt{\sum_{j=1}^{n} \beta_{j}^{2}}} .
\end{aligned}
$$

Then, this study can easily obtain the grey relational degree of each alternative onto the reference series. The normalized alternative series $\alpha$ will be closer to the reference series $\beta$ when the value of the grey relational degree is larger, and the alternative will be better.

4.2. MCGDM. MCGDM considers the problem of evaluating or selecting the best alternative(s) from a set of feasible alternatives according to the preferences provided by a group of experts, which are associated with incommensurate and conflicting criteria [78, 94-96]. The aim is to find the best satisfactory solution that increases the level of overall satisfaction with the final decision for a group of decisionmakers. A challenging problem that must be addressed when dealing with MCGDM problems is how to effectively aggregate individual preferences.

In this study, expected utility theory is used to aggregate individual preferences to form a group's consensus. This study first uses the utility function to measure personal preferences. Then, this paper uses expected utility theory to aggregate individual preferences per the von Neumann-Morgenstern utility theory. It is assumed that the decision-makers have a complete, reflexive, transitive, and continuous evaluation. In other words, the individual preferences can be described with the von Neumann-Morgenstern utility function that was expressed in Section 3.3, which can be restated as follows [85]:

$$
\begin{aligned}
U(x)= & \sum_{i=1}^{n} u\left(x_{i}\right) p\left(x_{i}\right), \quad(1 \leq i \leq n), \\
= & u\left(x_{1}\right) p\left(x_{1}\right)+u\left(x_{2}\right) p\left(x_{2}\right)+\cdots+u\left(x_{i}\right) \\
& p\left(x_{i}\right)+\cdots+u\left(x_{n}\right) p\left(x_{n}\right) .
\end{aligned}
$$

The expected utility is calculated by taking the weighted average of all possible outcomes. Each group member can be assigned a weight $p\left(x_{i}\right)$ ranging from 0 to 1 , which denotes her/his power in the group decision-making [85]. In this study, the utility function is defined as the revised GRA method. Thus, group decision-making with expected utility theory entails the sufficiency of reliability and belief in the process of aggregating multiple members' utilities. The aggregated utilities denote the group preferences over all criteria and alternatives. 


\section{Experiment}

In this section, a simulation experiment of an oil spill emergency management is designed to test and verify the revised GRA method and consensus-facilitating technique with expected utility theory. The aim is to propose and develop an effective new technique for crisis management in oil spill emergencies in a complex environment to reduce disaster risk.

5.1. Description of the Problem. An oil spill emergency can have a major impact on environmentally, ecologically, and economically sensitive marine areas and shorelines. To minimize the damage and pollution caused by oil spill accidents, it is necessary to develop an emergency plan for crisis management [9]. However, evaluating the best oil spill emergency plan is difficult because the plan depends on several variables within a changing and complex oil spill environment, such as quantity and type of oil spilled and location of oil spill, among other factors $[1,9]$. Moreover, the benefits and interests of the stakeholders (e.g., environmental agencies, oil companies, and nongovernmental organizations) involved in accidental oil spill incidents inevitably conflict in the decision-making process of choosing the best emergency alternative [9]. These factors motivate this research to find a new technique that can effectively handle variable factors with conflicting and incommensurate criteria. Hence, in this study, a revised GRA method for facilitating consensus is proposed and developed to aid the decision-makers who are involved in emergency planning for oil spill incidents.

5.2. Data and Criteria. Emergency response alternatives to oil spill accidents have been researched by simulating the trajectories of oil spills based on information about the quantity and type of the oil spill, the location of the oil spill, the spilled volume, the weather, and the oceanic conditions using the computational package OILMAP $[9,20]$. The main parameters of the oil spill response scenarios were defined in Ferreira [97] as the amount of oil at the coast $\left(C_{1}\right)$ and the amount of oil intercepted representing the amount of oil collected plus the amount of oil dispersed $\left(C_{2}\right)[9,97]$. The process of establishing a model for the MCGDM problem is composed of alternatives and criteria, which form the decision matrix. The decision matrix, consisting of 10 emergency response alternatives and two criteria, is shown in Table 1 [9].

5.3. Empirical Process. To demonstrate the feasibility and effectiveness of the proposed model, this section presents a simulation of oil spill emergency management to evaluate and select the best alternative to aid stakeholders involved in the emergency response for disaster risk reduction.

In the decision-making process during an oil spill emergency response, the opinions of the stakeholders (environmental agency: DM1; oil company: DM2; nongovernmental organization: DM3) on each criterion will usually differ. Therefore, a weight vector is expressed to define the importance of each criterion considering the opinions of the stakeholders. Nine levels of semantic importance for each criterion, which originated from the 1-9 scale of the analytic hierarchy process method [42], are assigned and defined as shown in Table 2. The stakeholders' semantic importance preferences are presented in the form of weights in Table 3.

The following procedures illustrate the feasibility and effectiveness of the proposed revised GRA method for group decision-making within a variable and complex oil spill environment with incommensurate and conflicting criteria and a group of stakeholders.

5.3.1. Standardize the Raw Matrix. The raw decision matrix, which consists of 10 emergency alternatives and two criteria, is presented in Table 1 . The criterion of oil at cost, $C_{1}$, is an $\mathrm{SB}$ criterion. The criterion of oil intercepted, $\mathrm{C}_{2}$, is an $\mathrm{LB}$ criterion. Hence, the normalized decision matrix can be calculated according to formulas (14)-(17). It is shown in Table 4.

5.3.2. Determine the Grey Relational Degree for the Stakeholders. Based on Tables 2 and 3, this paper can determine that the weight vector for $D_{1}$ is $w_{1}=\left(w_{11}, w_{12}\right)=(0.5,0.5)$; the weight vector for $\mathrm{DM}_{2}$ is $w_{2}=\left(w_{21}, w_{22}\right)=(0.1,0.9)$; and the weight vector for $\mathrm{DM}_{3}$ is $w_{3}=\left(w_{31}, w_{32}\right)=(0.8,0.2)$.

The grey relational degree for the three stakeholders can then be calculated using formulas (18)-(24). The results for $\mathrm{DM}_{1}, \mathrm{DM}_{2}$, and $\mathrm{DM}_{3}$ are given in Tables 5, 6, and 7, respectively.

5.3.3. Group Decision-Making with Expected Utility Theory. The von Neumann-Morgenstern utility theory assumes that the decision-makers have a complete, reflexive, transitive, and continuous evaluation. The weight vector of the three stakeholders in the simulation, namely, $\mathrm{DM}_{1}, \mathrm{DM}_{2}$, and $\mathrm{DM}_{3}$, is $w_{D M}=(0.3333,0.3333,0.3333)$, and it is assumed that the weight of expert opinion for the three stakeholders is equally important. In this study, the utility function is assumed as the function of the revised GRA method. Hence, the aggregated utilities, which denote the group preference over all alternatives and criteria, can be calculated by formula 25. The results are shown in Table 8 .

5.4. Analysis and Discussion of the Results. In Table 8, this study can see that the ranking of the 10 emergency alternatives is $8,9,10,7,3,6,5,1,2$, and 4 . The best emergency alternative is Alt. 8, followed by Alt. 9, Alt. 5, Alt. 10, Alt. 7, Alt. 6, Alt. 4, Alt. 1, Alt. 2, and Alt. 3. A visual analysis was also conducted, presented in Figure 1.

In a previous study, fuzzy TOPSIS for group decisionmaking was used to determine the best oil spill emergency alternative, with promising results [9]. The research results are the same as those of Krohling and Campanharo [9] in two respects: the best oil spill emergency alternative is the same, and the ranking of the 10 emergency alternatives is 
Table 1: Decision matrix consisting of emergency alternatives and criteria [9].

\begin{tabular}{lcc}
\hline Alternatives & Oil at cost: $C_{1}$ in $\mathrm{m}^{3}\left(\times 10^{3}\right)$ & Oil intercepted: $C_{2}$ in $\mathrm{m}^{3}\left(\times 10^{3}\right)$ \\
\hline Alt. 1 & 8.627 & 5.223 \\
Alt. 2 & 9.838 & 4.023 \\
Alt. 3 & 10.374 & 3.495 \\
Alt. 4 & 8.200 & 5.659 \\
Alt. 5 & 5.854 & 7.989 \\
Alt. 6 & 8.108 & 5.790 \\
Alt. 7 & 6.845 & 7.083 \\
Alt. 8 & 5.738 & 8.238 \\
Alt. 9 & 5.858 & 8.189 \\
Alt. 10 & 6.269 & 7.808 \\
\hline
\end{tabular}

TABLE 2: The importance of each criterion.

\begin{tabular}{lc}
\hline Numerical rating & Verbal judgments of importance \\
\hline 0.9 & Extremely important \\
0.8 & Very to extremely important \\
0.7 & Very important \\
0.6 & Moderately to very important \\
0.5 & Moderately important \\
0.4 & Slightly to moderately important \\
0.3 & Slightly important \\
0.2 & Low importance to slightly important \\
0.1 & Low importance \\
\hline
\end{tabular}

TABLE 3: The importance preferences of the stakeholders in the form of weights.

The stakeholders

Criteria

\begin{tabular}{lcc} 
& Oil at cost: $C_{1}$ & Oil intercepted: $C_{2}$ \\
\hline $\mathrm{DM}_{1}:$ Environment agency & Moderately important & Moderately important \\
$\mathrm{DM}_{2}:$ Oil company & Low importance & Extremely important \\
$\mathrm{DM}_{3}:$ Nongovernmental organization & Very to extremely important & Low importance to slightly important
\end{tabular}

TABLe 4: The normalized decision matrix.

\begin{tabular}{lcc}
\hline Alternatives & Oil at cost: $C_{1}$ & Oil intercepted: $C_{2}$ \\
\hline Alt. 1 & 0.3768 & 0.3643 \\
Alt. 2 & 0.1156 & 0.1113 \\
Alt. 3 & 0.0000 & 0.0000 \\
Alt. 4 & 0.4689 & 0.4563 \\
Alt. 5 & 0.9750 & 0.9475 \\
Alt. 6 & 0.4888 & 0.4839 \\
Alt. 7 & 0.7612 & 0.7565 \\
Alt. 8 & 1.0000 & 1.0000 \\
Alt. 9 & 0.9741 & 0.9897 \\
Alt. 10 & 0.8855 & 0.9093 \\
\hline
\end{tabular}

TABLE 5: Grey relational degree for $\mathrm{DM}_{1}$.

\begin{tabular}{lccc}
\hline Alternatives & $w_{11} C_{1}$ & $w_{12} C_{2}$ & Grey relational degree $\varepsilon_{1}$ \\
\hline Alt. 1 & 0.1540 & 0.1528 & 0.2170 \\
Alt. 2 & 0.1327 & 0.1324 & 0.1874 \\
Alt. 3 & 0.1250 & 0.1250 & 0.1768 \\
Alt. 4 & 0.1633 & 0.1619 & 0.2300 \\
Alt. 5 & 0.2439 & 0.2375 & 0.3404 \\
Alt. 6 & 0.1654 & 0.1649 & 0.2336 \\
Alt. 7 & 0.2018 & 0.2010 & 0.2849 \\
Alt. 8 & 0.2500 & 0.2500 & 0.3536 \\
Alt. 9 & 0.2437 & 0.2474 & 0.3473 \\
Alt. 10 & 0.2243 & 0.2292 & 0.3207 \\
\hline
\end{tabular}

TABLE 6: Grey relational degree for $\mathrm{DM}_{2}$.

\begin{tabular}{lccc}
\hline Alternatives & $w_{21} C_{1}$ & $w_{22} C_{2}$ & Grey relational degree $\varepsilon_{2}$ \\
\hline Alt. 1 & 0.0308 & 0.2751 & 0.2768 \\
Alt. 2 & 0.0265 & 0.2383 & 0.2397 \\
Alt. 3 & 0.0250 & 0.2250 & 0.2264 \\
Alt. 4 & 0.0327 & 0.2915 & 0.2933 \\
Alt. 5 & 0.0488 & 0.4276 & 0.4303 \\
Alt. 6 & 0.0331 & 0.2968 & 0.2986 \\
Alt. 7 & 0.0404 & 0.3619 & 0.3641 \\
Alt. 8 & 0.0500 & 0.4500 & 0.4528 \\
Alt. 9 & 0.0487 & 0.4454 & 0.4481 \\
Alt. 10 & 0.0449 & 0.4126 & 0.4150 \\
\hline
\end{tabular}


TABLE 7: Grey relational degree for $\mathrm{DM}_{3}$.

\begin{tabular}{lccc}
\hline Alternatives & $w_{31} C_{1}$ & $w_{32} C_{2}$ & Grey relational degree $\varepsilon_{3}$ \\
\hline Alt. 1 & 0.2464 & 0.0616 & 0.2540 \\
Alt. 2 & 0.2123 & 0.0531 & 0.2188 \\
Alt. 3 & 0.2000 & 0.0500 & 0.2062 \\
Alt. 4 & 0.2613 & 0.0653 & 0.2693 \\
Alt. 5 & 0.3902 & 0.0976 & 0.4022 \\
Alt. 6 & 0.2647 & 0.0662 & 0.2728 \\
Alt. 7 & 0.3229 & 0.0807 & 0.3328 \\
Alt. 8 & 0.4000 & 0.1000 & 0.4123 \\
Alt. 9 & 0.3899 & 0.0975 & 0.4019 \\
Alt. 10 & 0.3589 & 0.0897 & 0.3699 \\
\hline
\end{tabular}

TABLE 8: Group decision-making with expected utility theory.

\begin{tabular}{lcccc}
\hline Alternatives & $u(x 1) p(x 1)$ & $u(x 2) p(x 2)$ & $u(x 3) p(x 3)$ & $U(X)$ \\
\hline Alt. 1 & 0.0723 & 0.0923 & 0.0847 & 0.2492 \\
Alt. 2 & 0.0625 & 0.0799 & 0.0729 & 0.2153 \\
Alt. 3 & 0.0589 & 0.0755 & 0.0687 & 0.2031 \\
Alt. 4 & 0.0766 & 0.0978 & 0.0898 & 0.2642 \\
Alt. 5 & 0.1135 & 0.1434 & 0.1341 & 0.3909 \\
Alt. 6 & 0.0779 & 0.0995 & 0.0909 & 0.2683 \\
Alt. 7 & 0.0949 & 0.1214 & 0.1109 & 0.3272 \\
Alt. 8 & 0.1178 & 0.1509 & 0.1374 & 0.4062 \\
Alt. 9 & 0.1158 & 0.1493 & 0.1340 & 0.3991 \\
Alt. 10 & 0.1069 & 0.1383 & 0.1233 & 0.3685 \\
\hline
\end{tabular}

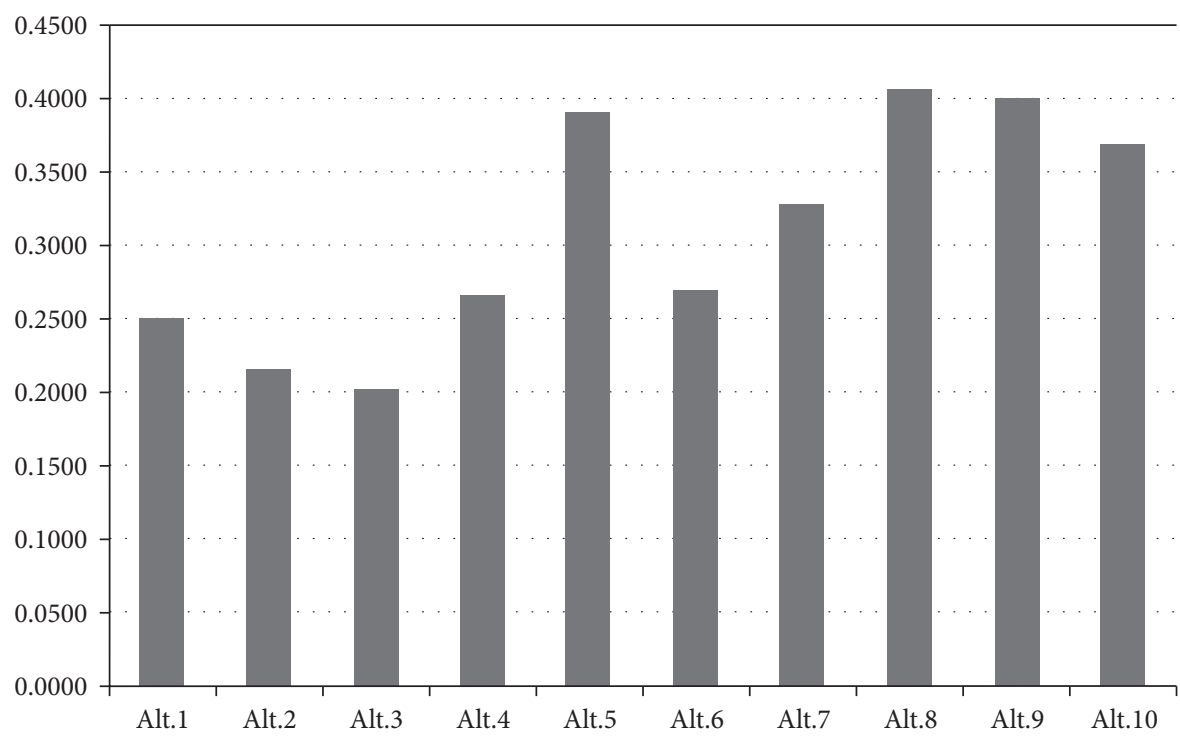

FIgURE 1: Oil spill emergency alternative evaluation.

also the same. In addition, the visual analysis that this paper presents in Figure 1 is the same as that in the work of Krohling and Campanharo [9], which verifies the feasibility and effectiveness of the proposed model for emergency response in the context of oil spill accidents.

\section{Conclusion}

Emergency management in response to oil spill accidents is a complex decision-making problem. How to effectively evaluate oil spill emergency alternatives for a complex environment to formulate crisis response strategies for disaster risk reduction has become a challenging issue worldwide. This study proposes and develops an effective technique, which is a revised GRA for facilitating a consensus response to an oil spill emergency. The advantages of this study are summarized as follows: Firstly, a revised GRA for group decision-making model is proposed to evaluate an emergency plan for responding to unexpected events related to an oil spill. Secondly, in this model, the concept of an angle 
between two vectors is applied to improve and optimize the GRA method by measuring the similarity between the reference series and alternative series. Thirdly, the expected utility theory is used to aggregate individual preferences and facilitate group consensus. Fourthly, the simulation experiment verified the feasibility and effectiveness of the proposed model by comparative analysis and visual analysis. Finally, in addition to oil spill scenarios, the proposed model can be used to solve other complex real-world problems that have a finite number of alternatives, multiple criteria, semantically stated benefits, multiple stakeholders' interests, and the need for emergency decisions under a variable and complex environment.

The main limitation of the proposed model is that there are few data samples and indicators. In future work, big data analysis methods will be further developed and proposed for emergency decisions under a variable and complex environment in order to reduce the impact of small sample sizes.

\section{Data Availability}

The data used to support the findings of this study are included within the article.

\section{Conflicts of Interest}

There are no conflicts of interest regarding the publication of this paper.

\section{Acknowledgments}

The author deeply acknowledges the financial support from the Less Developed Regions of National Natural Science Foundation of China (\#71761014) Guangzhou Philosophy and Social Sciences Development Planning Think Tank Project (\#2017GZZK53) and Education Science "13th FiveYear Plan" Research Project of Guangdong Province (2020GXJK384).

\section{References}

[1] X. Liu and K. W. Wirtz, "Decision making of oil spill contingency options with fuzzy comprehensive evaluation," Water Resources Management, vol. 21, no. 4, pp. 663-676, 2007.

[2] B. Baruque, E. Corchado, and A. Mata, "A forecasting solution to the oil spill problem based on a hybrid intelligent system," Information Sciences, vol. 180, no. 10, pp. 2029-2043.

[3] E. Iakovou, C. M. IP, C. Douligeris, and A. Korde, "Optimal location and capacity of emergency cleanup equipment for oil spill response," European Journal of Operational Research, vol. 96, no. 1, pp. 72-80, 1997.

[4] M. Lin, Z. Xu, Y. Zhai, and Z. Yao, "Multi-attribute group decision-making under probabilistic uncertain linguistic environment," Journal of the Operational Research Society, vol. 69, no. 2, pp. 157-170, 2017.

[5] M. Qiyas, M. A. Khan, S. Khan, and S. Abdullah, "Concept of Yager operators with the picture fuzzy set environment and its application to emergency program selection," International Journal of Intelligent Computing and Cybernetics, vol. 13, no. 4, pp. 455-483, 2020.
[6] M. W. Lin, C. Huang, and Z. S. Xu, "MULTIMOORA based MCDM model for site selection of car sharing station under picture fuzzy environment," Sustainable Cities and Society, vol. 53, Article ID 101873, 2020.

[7] H. Garg and R. Arora, "TOPSIS method based on correlation coefficient for solving decision-making problems with intuitionistic fuzzy soft set information," AIMS Mathematics, vol. 5, no. 4, pp. 2944-2966.

[8] W. Wu, Z. Xu, G. Kou, and Y. Shi, "Decision-making support for the evaluation of clustering algorithms based on MCDM," Complexity, vol. 2020, no. 2, 17 pages, Article ID 9602526, 2020.

[9] R. A. Krohling and V. C. Campanharo, "Fuzzy TOPSIS for group decision making: a case study for accidents with oil spill in the sea," Expert Systems with Applications, vol. 38, no. 4, pp. 4190-4197, 2011.

[10] K. J. Corchado and P. E. Chigbu, "On optimal control theory in marine oil spill management: a Markovian decision approach," European Journal of Operational Research, vol. 217, no. 2, pp. 470-478, 2012.

[11] S. Ko, W. Kim, S.-C. Shin, and J. Shin, "The economic value of sustainable recycling and waste management policies: the case of a waste management crisis in South Korea," Waste Management, vol. 104, pp. 220-227, 2020.

[12] H.-H. Lai, Y.-C. Lin, and C.-H. Yeh, "Form design of product image using grey relational analysis and neural network models," Computers \& Operations Research, vol. 32, no. 10, pp. 2689-2711, 2005.

[13] S.-J. Huang, N.-H. Chiu, and L.-W. Chen, "Integration of the grey relational analysis with genetic algorithm for software effort estimation," European Journal of Operational Research, vol. 188, no. 3, pp. 898-909, 2008.

[14] C. Oral, "Financial performance evaluation of sport clubs traded in borsa istanbul by using grey relational analysis," International Journal of Economics and Finance, vol. 8, no. 5, p. 293, 2016.

[15] W. Wu, Z. Xu, and G. K. Kou, "Evaluation of group decision making based on group preferences under a multi-criteria environment," Technological and Economic Development of Economy, vol. 26, no. 6, pp. 1187-1212, 2020.

[16] K.-E. Aslani, D. Chaidas, J. Kechagias, P. Kyratsis, and K. Salonitis, "Quality performance evaluation of thin walled PLA 3D printed parts using the taguchi method and grey relational analysis," Journal of Manufacturing and Materials Processing, vol. 4, no. 2, p. 47, 2020.

[17] X. F. Cheng, Z. Y. Shen, M. N. James, W. D. Li, and Y. X. Zhao, "Research on multi-attribute decision making using grey relation analysis, information axiom and fuzzy preferences," Advanced Materials Research, vol. 44-46, no. 46, pp. 587-594, 2008.

[18] H.-C. Liu, J.-X. You, X.-J. Fan, and Q.-L. Lin, “Failure mode and effects analysis using $\mathrm{D}$ numbers and grey relational projection method," Expert Systems with Applications, vol. 41, no. 10, pp. 4670-4679, 2014.

[19] K. Balaji, M. Siva Kumar, and N. Yuvaraj, "Multi objective taguchi-grey relational analysis and krill herd algorithm approaches to investigate the parametric optimization in abrasive water jet drilling of stainless steel," Applied Soft Computing, vol. 102, Article ID 107075, 2021.

[20] http://www.apsci.com.

[21] S. Tufekci and W. A. Wallace, "The emerging area of emergency management and engineering," IEEE Transactions on Engineering Management, vol. 45, no. 2, pp. 103-105. 
[22] G. Kou, Y. Shi, and S. Wang, "Multiple criteria decision making and decision support systems - guest editor's introduction," Decision Support Systems, vol. 51, no. 2, pp. 247-249, 2011.

[23] Y. Peng, G. Kou, G. Wang, W. Wu, and Y. Shi, "Ensemble of software defect predictors: an AHP-based evaluation method," International Journal of Information Technology \& Decision Making, vol. 10, no. 01, pp. 187-206, 2011.

[24] W. S. Wu and G. Kou, "A group consensus model for evaluating real estate investment alternatives," Financial Innovation, vol. 2, p. 8, 2016.

[25] K.-Y. Shen, S.-K. Hu, and G.-H. Tzeng, "Financial modeling and improvement planning for the life insurance industry by using a rough knowledge based hybrid MCDM model," Information Sciences, vol. 375, pp. 296-313, 2017.

[26] H. Arora, A. Keikha, and H. Mishmast Nehi, "Multiple-attribute decision-making problem using TOPSIS and choquet integral with hesitant fuzzy number information," Mathematical Problems in Engineering, vol. 2020, no. 2, pp. 1-12, 2020.

[27] M. Lin, H. Wang, and Z. Xu, "TODIM-based multi-criteria decision-making method with hesitant fuzzy linguistic term sets," Artificial Intelligence Review, vol. 53, no. 5, pp. 3647-3671, 2020.

[28] Y. Peng, Y. Zhang, and Y. Tang, "An incident information management framework based on data integration, data mining, and multi-criteria decision making," Decision Support Systems, vol. 51, no. 2, pp. 316-327, 2011.

[29] R. R. Kumar, S. Mishra, and C. Kumar, "Prioritizing the solution of cloud service selection using integrated MCDM methods under Fuzzy environment," The Journal of Supercomputing, vol. 73, no. 11, pp. 4652-4682, 2017.

[30] H. Li, L. Lv, F. Li, L. Wang, and Q. Xia, "A novel approach to emergency risk assessment using FMEA with extended MULTIMOORA method under interval-valued Pythagorean fuzzy environment," International Journal of Intelligent Computing and Cybernetics, vol. 13, no. 1, pp. 41-65, 2020.

[31] S. Opricovic and G.-H. Tzeng, "Compromise solution by MCDM methods: a comparative analysis of VIKOR and TOPSIS," European Journal of Operational Research, vol. 156, no. 2, pp. 445-455, 2004.

[32] J. L. Yang, H. N. Chiu, G.-H. Tzeng, and R. H. Yeh, "Vendor selection by integrated fuzzy MCDM techniques with independent and interdependent relationships," Information Sciences, vol. 178, no. 21, pp. 4166-4183, 2008.

[33] J. Chai, J. N. K. Liu, and E. W. T. Ngai, "Application of decision-making techniques in supplier selection: a systematic review of literature," Expert Systems with Applications, vol. 40, no. 10, pp. 3872-3885, 2013.

[34] K. M. N. K. Khalif, A. Gegov, and A. S. A. Bakar, "Hybrid fuzzy MCDM model for Z-numbers using intuitive vectorial centroid," Journal of Intelligent \& Fuzzy Systems, vol. 33, no. 2, pp. 1-15, 2017.

[35] R. Gao, H. Nam, W. Ko, and H. Jang, "Integrated system evaluation of nuclear fuel cycle options in China combined with an analytical MCDM framework," Energy Policy, vol. 114, pp. 221-233, 2017.

[36] C. Huang, M. Lin, and Z. Xu, "Pythagorean fuzzy MULTIMOORA method based on distance measure and score function: its application in multicriteria decision making process," Knowledge and Information Systems, vol. 62, no. 11, pp. 4373-4406, 2020.

[37] J. Wallenius, J. S. Dyer, P. C. Fishburn, R. E. Steuer, S. Zionts, and K. Deb, "Multiple criteria decision making, multiattribute utility theory: recent accomplishments and what lies ahead," Management Science, vol. 54, no. 7, pp. 1336-1349, 2008.

[38] J. S. Dyer, P. C. Fishburn, R. E. Steuer, J. Wallenius, and S. Zionts, "Multiple criteria decision making, multiattribute utility theory: the next ten years," Management Science, vol. 38, no. 5, pp. 645-654, 1992.

[39] L. Li, L. A. Rodríguez-Picón, A. Alvarado-Iniesta, C. D. Luviano, and Z. Xu, "MOORA under pythagorean fuzzy set for multiple criteria decision making," Complexity, vol. 2018, Article ID 2602376, 10 pages, 2018.

[40] W. Wu and Z. Xu, "Hybrid TODIM method with crisp number and probability linguistic term set for urban epidemic situation evaluation," Complexity, vol. 2020, no. 4, 11 pages, 2020.

[41] A. Charnes, W. W. Cooper, and E. Rhodes, "Measuring the efficiency of decision making units," European Journal of Operational Research, vol. 2, no. 6, pp. 429-444, 1978.

[42] T. L. Saaty, The Analytic Hierarchy Process, McGraw-Hill, New York, NY, USA, 1980.

[43] J. Deng, "Control problems of grey systems," Systems and Control Letters, vol. 1, pp. 288-294, 1982.

[44] C. L. Hwang and K. Yoon, Multiple Attribute Decision Making Methods and Applications, Springer, Berlin, Germany, 1981.

[45] E. Fontela and A. Gabus, "DEMATEL: progress achieved," Futures, vol. 6, no. 4, pp. 361-363, 1974.

[46] J. P. Brans, B. Mareschal, and P. H. Vincke, "PROMETHEE-a new family of outranking methods in multi-criteria analysis," Operations Research, vol. 84, pp. 447-490, 1984.

[47] R. Keeney and H. Raiffa, Decisions with Multiple Objectives: Preferences and Value Tradeoffs, Wiley, New York, NY, USA, 1976.

[48] C. M. Fonseca and P. J. Fleming, "Genetic algorithms for multi-objective optimization: formulation, discussion, and generalization," pp. 416-423, Morgan Kaufmann, San Mateo, CA, USA, 1993.

[49] R. Krohling and D. Rigo, "Fuzzy group decision making for management of oil spill responses," in Applications of soft computing: From theory to praxis, J. Mehnen, Ed., vol. 58, pp. 3-12, Springer-Verlag, Berlin, Germany, 2009.

[50] R. R. Yager, "Non-numeric multi-criteria multi-person decision making," Group Decision and Negotiation, vol. 2, no. 1, pp. 81-93, 1993.

[51] G. Fu, "A fuzzy optimization method for multicriteria decision making: an application to reservoir flood control operation," Expert Systems with Applications, vol. 34, no. 1, pp. 145-149, 2008.

[52] W. Wu, G. Kou, and Y. Peng, "Group decision-making using improved multi-criteria decision making methods for credit risk analysis," Filomat, vol. 30, no. 13, pp. 4135-4150, 2016.

[53] V. Maliene, R. Dixon-Gough, and N. Malys, "Dispersion of relative importance values contributes to the ranking uncertainty: sensitivity analysis of Multiple Criteria DecisionMaking methods," Applied Soft Computing, vol. 67, pp. 286-298, 2018.

[54] S. Wan, L. Zhong, and J. Dong, "A new method for group decision making with hesitant fuzzy preference relations based on multiplicative consistency," IEEE Transactions on Fuzzy Systems, vol. (99), p. 1, 2019.

[55] J. Deng, "Introduction to grey theory system," The Journal of Grey System, vol. 1, no. 1, pp. 1-24, 1989.

[56] R. Rajesh and V. Ravi, "Supplier selection in resilient supply chains: a grey relational analysis approach," Journal of Cleaner Production, vol. 86, pp. 343-359, 2015. 
[57] H. Malekpoor, K. Chalvatzis, N. Mishra, M. K. Mehlawat, D. Zafirakis, and M. Song, "Integrated grey relational analysis and multi objective grey linear programming for sustainable electricity generation planning," Annals of Operations Research, vol. 269, no. 1-2, pp. 475-503, 2017.

[58] C. Hamzaçebi and M. Pekkaya, "Determining of stock investments with grey relational analysis," Expert Systems with Applications, vol. 38, no. 8, pp. 9186-9195, 2011.

[59] J. Shi, Z. Ding, W.-J. Lee, and Y. Yang, "Forecasting model for very-short term wind power forecasting based on grey relational analysis and wind speed distribution features," IEEE Transactions on Smart Grid, vol. 5, no. 1, pp. 521-526, 2014.

[60] W. Wu, "Grey relational analysis method for group decision making in credit risk analysis," EURASIA Journal of Mathematics, Science and Technology Education, vol. 13, no. 12, pp. 7913-7920, 2017.

[61] K. Vatansever and Y. Akgül, "Performance evaluation of websites using entropy and grey relational analysis methods: the case of airline companies," Decision Science Letters, vol. 7, no. 2, pp. 1-12, 2018.

[62] J. T. Huang and Y. S. Liao, "Optimization of machining parameters of wire-EDM based on grey relational and statistical analyses," International Journal of Production Research, vol. 41, no. 8, pp. 1707-1720, 2003.

[63] L.-C. Hsu and C.-H. Wang, "Forecasting integrated circuit output using multivariate grey model and grey relational analysis," Expert Systems with Applications, vol. 36, no. 2, pp. 1403-1409, 2009.

[64] S. f. Liu, N. m. Xie, and J. Forrest, "Novel models of grey relational analysis based on visual angle of similarity and nearness," Grey Systems: Theory and Application, vol. 1, no. 1, pp. 8-18, 2011.

[65] W. Wu and Y. Peng, "Extension of grey relational analysis for facilitating group consensus to oil spill emergency management," Annals of Operations Research, vol. 238, no. 1-2, pp. 615-635, 2016.

[66] X. Y. Zhang and J. Q. Wang, "Consensus-based framework to MCGDM under multi-granular uncertain linguistic environment," Journal of Intelligent \& Fuzzy Systems, vol. 33, no. 2, pp. 1-12, 2017.

[67] Q. Xu and $\mathrm{K} . \mathrm{Xu}$, "Mine safety assessment using gray relational analysis and bow tie model," PLoS One, vol. 13, no. 3, Article ID e0193576, 2018.

[68] K. Zhang, "Grey relation theory and its applications. First international symposium on uncertainty modeling and analysis," Small Ruminant Research-Small Ruminant Res. vol. 404-408, 1991.

[69] J. J. H. Liou, C.-C. Hsu, W.-C. Yeh, and R.-H. Lin, "Using a modified grey relation method for improving airline service quality," Tourism Management, vol. 32, no. 6, pp. 1381-1388, 2011.

[70] N. Xie, Z. Li, and G. Zhang, "An intuitionistic fuzzy soft set method for stochastic decision-making applying prospect theory and grey relational analysis," Journal of Intelligent \& Fuzzy Systems, vol. 33, no. 1, pp. 15-25, 2017.

[71] L. A. Sidorov, Angle in Hazewinkel, Michiel, Encyclopedia of Mathematics, Springer, New York, NY, USA, 2001.

[72] G. Pasi and R. Yager, "Modeling the concept of majority opinion in group decision making," Information Sciences, vol. 176 , no. 4 , pp. $390-414,2006$.

[73] B. Vahdani, S. M. Mousavi, R. Tavakkoli-Moghaddam, and H. Hashemi, "A new design of the elimination and choice translating reality method for multi-criteria group decision- making in an intuitionistic fuzzy environment," Applied Mathematical Modelling, vol. 37, no. 4, pp. 1781-1799, 2013.

[74] M. Dan and P. Zheng, "On weighted unbalanced linguistic aggregation operators in group decision making," Information Sciences, vol. 223, pp. 31-41, 2013.

[75] D. K. Joshi and S. Kumar, "Entropy of interval-valued intuitionistic hesitant fuzzy set and its application to group decision making problems," Granular Computing, vol. 3, no. 4, pp. 367-381, 2018.

[76] A. Ishizaka and A. Labib, "Review of the main developments in the analytic hierarchy process," Expert Systems with Application, vol. 38, pp. 14336-14345, 2011.

[77] W. Wu, G. Kou, Y. Peng, and D. Ergu, "Improved AHP-group decision making for investment strategy selection," Technological and Economic Development of Economy, vol. 18, no. 2, pp. 299-316, 2012.

[78] W. Wu, G. Kou, and Y. Peng, "A consensus facilitation model based on experts' weights for investment strategy selection," Journal of the Operational Research Society, vol. 69, no. 9, pp. 1435-1444, 2018.

[79] P. Mongin, "Expected utility theory," in Handbook of Economic Methodology, J. Davis, W. Hands, and U. Maki, Eds., Edward Elgar Publishing, pp. 342-350, Cheltenham, UK, 1997.

[80] B. P. M. Duarte, “The expected utility theory applied to an industrial decision problem - what technological alternative to implement to treat industrial solid residuals," Computers \& Operations Research, vol. 28, no. 4, pp. 357-380, 2001.

[81] C. Starmer, "Developments in non-expected utility theory: the hunt for a descriptive theory of choice under risk," Journal of Economic Literature, vol. 38, no. 2, pp. 332-382, 2000.

[82] W. Buchholz and M. Schymura, "Expected utility theory and the tyranny of catastrophic risks," Ecological Economics, vol. 77, pp. 234-239, 2012.

[83] H. Markowitz, "Mean-variance approximations to expected utility," European Journal of Operational Research, vol. 234, no. 2, pp. 346-355, 2012.

[84] K. Arrow and R. Lind, "Uncertainty and the evaluation of public investment decisions," American Economic Review, vol. 60 , pp. 364-378, 1970.

[85] J. Li, G. J. Davies, G. Kendall et al., "Evidence and belief in regulatory decisions - incorporating expected utility into decision modelling," Expert Systems with Applications, vol. 39, no. 10, pp. 8604-8610, 2012.

[86] G. Geiger, "Multi-attribute non-expected utility," Annals of Operations Research, vol. 196, no. 1, pp. 263-292, 2012.

[87] J. L. Von Neumann and O. Von Morgenstern, Theory of Games and Economic Behavior, Princeton University Press, Princeton, NJ, USA, 1944.

[88] J. Liang and J. Pang, "Evaluation of the results of multi-attribute group decision-making with linguistic information," Omega, vol. 40, no. 3, pp. 294-301, 2012.

[89] N. C. Chatterjee and G. K. Bose, "A COPRAS-F base multicriteria group decision making approach for site selection of wind farm," Decision Science Letters, vol. 2, no. 1, pp. 1-10, 2013.

[90] X. Zhang, F. Jin, and P. Liu, "A grey relational projection method for multi-attribute decision making based on intuitionistic trapezoidal fuzzy number," Applied Mathematical Modelling, vol. 37, no. 5, pp. 3467-3477, 2013.

[91] C. C. Sun, "Combining grey relation analysis and entropy model for evaluating the operational performance: an empirical study," Quality \& Quantity, vol. 48, no. 3, pp. 1589-1600, 2014. 
[92] Z. Xu and Q. Da, "Projection method for uncertain multiattribute decision making with preference information on alternatives," International Journal of Information Technology \& Decision Making, vol. 03, no. 03, pp. 429-434, 2004.

[93] G. Zheng, Y. Jing, H. Huang, and Y. Gao, "Application of improved grey relational projection method to evaluate sustainable building envelope performance," Applied Energy, vol. 87, no. 2, pp. 710-720, 2010.

[94] C. L. Hwang and M. J. Lin, Group Decision Making under Multiple Criteria: Methods and Applications, Springer-Verlag, Berlin, Germany, 1987.

[95] D. C. Morais and A. T. de Almeida, "Group decision making on water resources based on analysis of individual rankings," Omega, vol. 40, no. 1, pp. 42-52, 2012.

[96] X. Chen, W. Xu, H. Liang, and Y. Dong, "The classificationbased consensus in multi-attribute group decision-making," Journal of the Operational Research Society, vol. 71, 2019.

[97] J. P. Ferreira, "Analysis of response strategies to oil spills at the coast of espirito santo using computational modeling," MSc. Thesis, Environmental Engineering Graduate Program, Brazil, 2006. 